\title{
THE DARK SIDE OF THE BREASTFEEDING: IN THE LIGHT OF ENDOCRINE DISRUPTORS
}

\author{
Marouane Chemek $^{1}$, Jan Nevoral ${ }^{1,2}$
}

\begin{abstract}
Breastfeeding plays an essential role in the healthy development of a newborn, but human milk is obviously compromised by pollutants from our environment. The main contaminants of human milk with endocrine-disrupting compound (EDCs) have raised concern for public and environmental health. Bisphenol A (BPA), which can leach from plastics, are among the most well-studied. Since EDs are known to cross the mammary gland barrier and BPA may accumulate in the neonate, "BPA-free" products have been introduced to the market. However, recent studies have shown that alternative bisphenols (e.g. BPS, BPF) can be detected in breast milk, have ED activities and may have developmental effects similar to BPA.
\end{abstract}

Running title: Endocrine disruptors and breastfeeding

Keywords: endocrine disruptors, bisphenols, breastfeeding, development 


\section{Introduction}

Accumulating research shows that environmental stressors during gestation, infancy, and early childhood are risk factors for diseases in adulthood. Endocrine disrupting chemicals (EDCs) are a class of stressor that could affect the normal growth and development process and increase the risk of disease across the lifespan by altering the homeostasis or action of endogenous hormones of the endocrine system $[1,2]$. Humans may encounter EDCs daily and during all stages of life, from conception and fetal development to adulthood and senescence. Nevertheless, prenatal and early postnatal windows are the most critical for proper development. The fetus, infant, and child may have higher exposure to some EDCs than adults because of developmentally-appropriate differences in diet, behaviour, physiology, anatomy, and toxicokinetics [3].

Among representative EDCs are Bisphenol A (BPA) [4] and its analogues (BPS, BPF) which have shown similar endocrine-disrupting effects to BPA [5]. Infants and children were exposed to Bisphenols (BPs) through several routes, including gestational and lactational transfer, inhalation and ingestion of contaminated dust, dermal exposure, and oral exposures through food and beverage containers/films [6-8]. However, the transplacental and lactational exposure as the most relevant exposure for fetus and neonates, respectively, is considered.

This review aims to summarize some of developmental "toxicity" due to exposure to EDCs during pregnancy and lactation taking as an example widely-used BPs. The developmental effects of very low doses of BPs are underlined, with emphasis on favourable breastfeeding as a route of the exposure, with several unique features.

\section{Susceptibility to EDCs during early development}

Although the majority of the human population is exposed to EDCs, particular concern has arisen regarding the potential effects of exposure to EDCs during early development. There are three principal reasons why the impact of EDCs may be more apparent on the developing fetus and the postnatal offspring. Firstly, many of the normal homeostatic endocrine feedback mechanisms and the detoxification ability are not fully developed, and many low dose exposures have more adverse effects on the developing fetus than adult ones [9]. Secondly, it appears that one of the characteristics of the EDCs is that the binding affinity of these compounds to sex hormone binding globulin is low. Hence, the metabolism of these compounds in the fetus maybe particularly low [10]. Thirdly, while the mother may have been exposed to these compounds at low exposure levels during life, these compounds tend to be highly lipophilic, and some of them are accumulated in fat stores in the body [11]. These stores maybe rapidly mobilized during the energetically-expensive periods of pregnancy, and in particular lactation, and they exert endocrine disrupting effects in late pregnancy and post-natal life [12]. Hence, the underdeveloped organism maybe exposed to unusually high concentrations of compounds that cannot be easily metabolized or excreted at these stages of development. Moreover, breast milk represents exclusive food for a nursed child and, therefore, this specific route of exposure of neonates seems to be genuinely dangerous for further development of the body.

\section{Two points of view on breastfeeding in the age of plastics}

Most environmental pollutants are omnipresent and detected even in oceans, glaciers and rocks. The recent age can be called the "age of plastics" and, therefore, mankind is exposed widely and systematically every day, in particular, through daily needs items. Human milk nowadays has been unintentionally compromised by pollutants from our environment, as a result of living in a 'modern' industrialized world [13]. The focus of attention on environmental chemicals in human milk can obscure the fact that human milk confers numerous and well-documented health benefits to a nursing infant. When considering the potential risks associated with environmental chemicals in human milk, it is equally important to consider the benefits associated with breast-feeding. In this way, a balanced picture of the advantages and disadvantages of breastfeeding will be mentioned in the following section.

Human milk is a biological fluid synthesized in the mammary tissue by cellular mechanisms delicately designed to provide the infant with the precise quantitative and qualitative growth- and immune-enhancing factors, while at the same time enhancing mother-child bonding. Because human milk provides a superior nutrition source for an infant, breast-feeding remains the preferred choice for infant nutrition. In fact, human milk contains nutritive (e.g. lipids, carbohydrates, proteins, amino acids, minerals, and vitamins) and non-nutritive (e.g. enzymes, immunoglobulins, nucleic acids, hormones, growth factors, and cells, including macrophages, lymphocytes, and epithelial cells) constituents that both contribute to the infant's well-being [14]. The American Academy of Pediatrics (AAP) "recommends breast milk as the preferred source of feeding for almost all babies for at least the first year of life" because "breast-feeding provides health, nutritional, immunologic, developmental, psychological, social, economic and environmental advantages unmatched by other feeding options", and "epidemiologic research shows that human milk and breast-feeding provide advantages with 
regard to general health, growth, and development, while significantly decreasing risk for a large number of acute and chronic diseases" [15]. Therefore, it is obvious that maternal benefits include more rapid postpartum recovery, increased child spacing, decreased risk of osteoporosis, lower incidence of both breast cancer and ovarian cancer, an earlier return to pre-pregnancy weight, and emotional benefits such as empowerment and mother-infant bonding [16].

On the other hand, breastmilk represents a vehicle for many compounds which the mother eats and/or is exposed to. Since the 1800s, maternal milk has been known to contain chemical contaminants that could adversely affect nursing infants, and potentially hazardous persistent environmental chemicals were first detected in the 1950s [17] Thus, breastfeeding, in addition to its beneficial properties, can potentially cause high-dose exposure of chemical pollutants to neonates, which can be more susceptible to adverse effects resulting from chemical exposures than adults due to the rapid mental and physical changes that take place during the prenatal and neonatal periods $[3,18]$. Most of the research on environmental chemicals in human milk has concentrated on a group of chemicals referred to as persistent, bioaccumulative, and toxic (PBT) [14]. There are both practical and health-related reasons for concentrating on PBT chemicals. One practical reason is that these chemicals tend to be lipophilic ("fat-loving") and persistent. The PBTs include parabens, octylphenols, BPs, dioxins, furans, dichlorophenylcloroethane (DDT), organochlorine cyclodienes, semi-volatile organohalogens, heavy metals, pesticides, volatile and other organic compounds [19].

\section{Lactational transfer of toxic chemicals into breast milk}

Some indication of the potential excretion of chemicals into breast milk may be obtained by considering the theoretical aspects of drug transfer [20]. The alveolar cells of the mammary glands are the interface between maternal blood and milk, and substrates for milk production and xenobiotics are brought to the alveoli by the bloodstream. About 3 to 4 percent of milk consists of lipids; therefore, transfer of lipid-soluble non-ionized chemicals by passive diffusion through the membrane is favoured. The lipid soluble chemicals diffuse along with fats from plasma into the mammary gland and are excreted with milk during lactation. Several other mechanisms including exocytosis (for water-soluble components), the carrier mediated transport system and active transport (for small ions and molecules), and pinocytosis and paracellular movement $[20,21]$ have also been implicated.

The overall rate and extent of accumulation of chemicals in the milk compartment and subsequent exposure is controlled by maternal factors, infant factors, and chemical physiochemical properties. Maternal endogenous factors include age, general physiological status, uncommon auto-immune properties, thyroid disorder and dietary habits, history of smoking in the year before pregnancy, consumption of alcohol during the first trimester of pregnancy, number of pregnancies, history of previous deliveries and lactation, duration of lactation and the number of children being breastfed at one time $[22,23]$. Infant factors affecting exposure include the suckling pattern (the volume of milk consumed, frequency, and timing relative to maternal plasma concentrations) and xenobiotics oral bioavailability in the neonate [24]. Chemicals physiochemical properties are determined by factors such as ionization, plasma protein binding, molecular weight, drug lipophilicity and its pharmacokinetics in the mother [25]. Global environmental conditions (temperature, pressure) and individual exposure conditions (degree and duration of maternal exposure, presence and levels of xenobiotic) may also alter uptake, distribution, biotransformation, and excretion of the toxic chemical [26]. Furthermore, milk composition changes over time (colostrum, transitional milk and mature milk) and during a single suckling (foremilk, hindmilk). The first postpartum week colostrum has a high protein $(10 \%)$ and a low fat (1\%) content; however, mature milk has a low protein $(1 \%)$ and a high fat $(4 \%)$ level. Because of the high protein content in colostrum, chemicals with high protein binding may be more likely to pass into human milk at this time [14].

\section{Occurrence of EDCs in milk and toxicokinetics}

Due to its fat content, both breast and dietary milk could be polluted by many xenobiotics characterized by lipophilic properties [27,28]. Breast milk, milk from lactating cows and dairy products are widely consumed by infants, and many adults throughout the world, and the occurrence of quantifiable amounts of EDCs has raised concern for public and environmental health [29]. BPA is considered an endocrine-disrupting chemical that has the efficacy of the hormone estradiol in some tissues and antagonizes thyroid hormone action in addition to its antagonizing androgenic action [4]. BPA is found in dentistry composites, paints, plastics, and toys and is used to cover food and beverage cans, polycarbonate beverage bottles and, not long ago, baby bottles and infant formula packaging. In 2010, the World Health Organization [30] estimated that breastfed infants between the ages of 0-6 months were exposed to $0.3 \mu \mathrm{g} / \mathrm{kg}$ body weight (BW) BPA daily, and BPA levels in infants fed a formula from polycarbonate bottles were estimated at eight times breast-fed concentrations, and those given a canned formula in polycarbonate-free bottles were exposed to $0.5 \mu \mathrm{g} / \mathrm{kg} \mathrm{BW}$ [30]. 
Following oral administration in live animals and humans, BPA is completely and rapidly absorbed from the gastrointestinal tract. Hepatic clearance of BPA to its glucuronidated metabolite (BPA-Glu) is rapid and complete, and BPA-Glu is the predominant substance found in plasma. Urinary excretion is the only way to eliminate BPA-Glu. Adult human studies have reported that BPA has a very short half-life and conjugate forms of BPA are excreted into urine with a half-life of $<6 \mathrm{~h}$ [31]. However, in the case of the specific populations, such as developing fetuses, growing infants, and young children, whose chemical metabolizing systems (glucuronidation activity) are underdeveloped, even moderate exposure can lead to higher internal concentration of BPA [32,33]. In recent years, use of physiologically based pharmacokinetic (PBPK) modelling has been quite popular in human health risk assessment [34,35]. Most publications addressed PBPK modelling of BPA adult exposure $[33,36]$. Few studies have addressed BPA pharmacokinetic during the gestation [35] and lactation period [32,37]. During breastfeeding, the absorbed portion of BPA is quickly transferred into the breast by passive diffusion, resulting in the observed high concentration of BPA in the human milk quickly (hours) after BPA consumption [23]. This is due to the high lipophilicity of this chemical (octanol-water coefficient $\mathrm{K}_{\text {ow }}: 2.2-3.4$ ), which incorporates into human milk at levels comparable to the concentrations in fatty tissues in the body [38]. Many studies reported the occurrence of different levels of BPA in colostrum and human milk. BPA is present in human milk in an unconjugated or conjugated form [39]. However, conjugated BPA does not display any estrogenic activity [38]; consequently, the measurement of unconjugated-BPA (u-BPA) is more suitable in the risk assessment of BPA in breastfeeding infants. BPA in mature milk reflects the recent exposure of the mother. This is different from BPA content in colostrum, which reflects accumulated mother exposure during the second half of the pregnancy [38]. In addition to contamination of breast milk by BPA, several studies suggest that BPA, even at low doses, can affect mammary gland development $[40,41]$ and leads to the development of breast cancer during adulthood [42-44]. Furthermore, rats exposed to BPA in the womb presented abnormalities in adult mammary tissue and alterations in the milk protein content by the time they were feedings their pups [45]. Considering that BPA is an EDC, after birth, BPA exposure alters sensitivity to estradiol-dependent mammary gland development and progesterone-dependent mammary cell proliferation [46]. Estrogenic and anti-androgenic potencies of BPs other than BPA (BPA analogues) have been the subject of recent intense investigations. Several studies showed that BPS, BPF and BPAF exert estrogenic effects and partly exert anti-androgenic and thyroid- disrupting effects with potencies similar to or higher than those of BPA [5, 47]. The metabolism and distribution of BPA analogues in humans have not been as well studied as in case of BPA; nevertheless, some experiments suggest that BPF and BPS metabolism is similar to BPA metabolism [5]. Moreover, to our best knowledge, only few studies [48-51] are focused on bisphenol analogues in breast milk.

\section{Developmental effect of BPs \\ Effect on growth and development}

Several emerging concerns pertaining to BPs exposure during early development have the potential for these EDCs to contribute to changes in body weight. Many studies performed with rodents have demonstrated increases in body weight of the male and female offspring issued from mother rodent exposed to a low dose of BPA during gestation and or lactation periods [52]. There are few toxicological data on BPA analogues from in vivo experiments on physiological functions like energetic metabolism. The study of Ivry del Moral et al. [53] demonstrated for the first time that perinatal exposure to low doses of BPS induced a significant overweight in male mice. BPA may exert obesogenic effects through various pathways, including via its activity as an estrogen and glucocorticoid receptor agonist, as well as by interference with thyroid hormone pathways and by activation of peroxisome proliferator-activated receptor- $\gamma$ (PPAR $\gamma$ ) [54]. In-depth characterizations of growth and development following BPA analogues exposure have been also conducted, with many consequences discussed below.

\section{Effect on nervous system development and behaviour}

BPs exposure affects the nervous system physiology at all life stages. Vulnerability is higher in the developing brain due to the lipophilic chemical structure that allows it to easily cross the blood-placental and blood-brain barriers, as well as to be delivered to offspring through lactation [55]. Emerging research on maternal EDCs exposure and child neurodevelopmental outcomes have recently found significant associations between prenatal and postnatal BPA exposure and long-term alterations in offspring behaviour, mainly including three behavioural categories: anxiety and exploration, learning and memory, and socio-sexual behaviours across mammalian species $[56,57]$. In addition, several studies in rodents confirmed that exposure during gestation and lactation period to a low, but environmentally relevant BPA dose, produced subtle alterations in maternal behaviour, including reduction of subsequent maternal nursing behaviour and an increase in time spent away from the nest over the first two weeks post-partum. Early life BPA exposure may also decrease the female offspring engagement in maternal cares in mice and rats [58], indicating the transgeneration- 
al impact of BPA exposure on the neuroendocrine substrates modulating maternal behaviour. Several studies have suggested that BPA analogue might be also toxic to the nervous system and affect animal behaviour. BPS exposure was found to alter behaviour in terms of increased anxiety and reduced interest in social interactions in rats $[59,60]$. Recently, BPS and BPF were also found to affect dopamine (DA) - and serotonin (5-HT)-related genes, and the neuro-steroidogenesis-related enzyme, $5 \alpha$-reductase $(5 \alpha-\mathrm{R})$, in the prefrontal cortex of juvenile female rats due to maternal exposure [61].

\section{Effect on male and female reproductive system development}

Experimental studies on the effects of BPs on the reproduction of male rodents have revealed an adverse influence on the development of the testes and on the spermatogenesis of adult individuals following prenatal in utero or early postnatal exposure. Exposure to BPA during the period of development of the testes is frequently linked to a range of negative effects in adult testes, e.g. decreased levels of testicular testosterone, decreased weights of the epididymis and seminal vesicles, a decrease in daily sperm production per gram testis, and increased weights of the prostate and preputial [62]. Recent animal studies reported that both prenatal and postnatal exposure to low-dose BPA decreased sperm numbers and alter early male sexual development $[63,64]$. Additionally, induction of testicular oxidative stress or apoptosis was observed in mice and rats exposed to low-dose BPA during the prenatal or postnatal periods [65]. Few studies have indicated that low-dose BPA exposure potentially altered the epigenetic pattern in the testes, including increased rates of methylation of Insulin like growth factor-2 (IGF2) and decreased protein lysine acetylation levels in rats $[66,67]$. Overall, the strength regarding current evidence for risk assessment regarding low dose BPA exposure is still limited. Concerning the female reproductive system, experimental studies in rodents have indicated that prenatal and postnatal exposure to low dose BPA resulted in decreased ovarian weights, follicle numbers, and primordial follicle recruitment in Wistar rats, as well as increasing the number of corpora lutea and causing a delay in vaginal opening [68,69]. Additionally, Calhoun et al. reported that early life exposure to BPA via food consumption altered three genes (Hoxa13, Wnt4 and Wnt5a) involved in reproductive organ development in rhesus macaque uterus [70]. A study regarding BPA exposure on the ovaries of F1 generation mice resulted in a non-monotonic dose-relationship with several transgenerational effects found in the F3 generation [71].

Regarding BPA analogues, only few studies have examined the effects of these BPs on female and the male reproductive systems. BPS elicits repro- ductive and germline toxicity in Caenorhabditis elegans [72]. This reproductive influence was also seen in some mice experiments. Recent studies have reported that prenatal and postnatal exposure to BPA analogues disrupts adult reproductive functions in male and female mice [73-75]. Specifically, BPE and BPS in addition to BPA impair estrous cyclicity, follicle counts, steroidogenesis, and fertility in female mice [75]. More importantly, the results of these recent studies suggest that prenatal exposure to BPA analogues (BPE and BPS) transgenerationally affects female reproductive functions [76]. These results support recent reports that BPS affects female puberty onset and estrous cyclicity in rats [77], mouse and porcine oocytes [78,79] and estradiol-17 $\beta$ production in bovine granulosa cells [80]. Concerning the male reproductive system, the same authors have found that postnatal exposure to BPE and BPS impairs spermatogenic output and motility, and induces alterations of the spermatogenesis [74].

\section{Conclusion and Perspectives}

Breastfeeding potentially causes high-dose exposure of chemical pollutants including EDCs. The levels of environmental chemicals are influenced by global and local use patterns of chemicals, and furthermore by diet, maternal age, parity and duration of lactation. The benefits of breastfeeding outweigh any potential risk associated with this practice, but close surveillance is needed to keep it as contaminant free as possible. Although BPA is being replaced by its analogues (BPS and BPF), recent reported detections of BPA analogues in human milk associated with some developmental effect, create a compelling reason to increase research on the health effects of these chemicals during early life. Moreover, increase monitoring efforts (breast milk analyses), toxicokinetics (the appropriate breastfeeding PBTK models are still lacking), and design experimental work describing molecular action are needed for the elimination of deleterious effects. Taken together, this review appeal to the other side of the breastfeeding: in addition to its beneficial effect, the negative effect of endocrine disruptors on infant health should be considered. Moreover, in the light of endocrine disruptors, breast milk donation and/or sharing programme should be subjected to a control and avoid milk contaminated with pollutants.

\section{Ethical approval}

The conducted research is not related to either human or animal use.

\section{Acknowledgements}

The research of bisphenols is supported by the Czech Health Research Council (NV18-01-00544), European Human Biomonitoring Initiative HBM4EU provided by H2020, the Charles University Research Fund (Progres Q39); the National Sustainability Programme I (NPU I) Nr. LO1503 and the project No. CZ.02.1.0 
1/0.0/0.0/16_019/0000787 "Fighting Infectious Diseases", both provided by the Ministry of Education, Youth and Sports of the Czech Republic.

We would like to thank to prof. Jaroslav Petr and Dr. Tereza Zalmanova (Institute of Animal Science, Prague, Czech Republic), and Dr. Michal Jeseta (University Hospital of Masaryk University, Brno, Czech Republic), for kind help with bisphenols' project leading and development.

\section{Corresponding author}

Marouane Chemek, Ph.D., Biomedical Center, Faculty of Medicine in Pilsen, Charles University, alej Svobody 1655/76, Czech Republic, phone: +420 776215 224, email: chemekm@yahoo.com.

\section{Conflict of interest statement}

The authors declare they have no conflict of interest.

\section{References}

1. Botton J, Kadawathagedara M, de Lauzon-Guillain B. Endocrine disrupting chemicals and growth of children. Ann Endocrinol (Paris) 2017;78(2):108-11; DOI: 10.1016/j.ando.2017.04.009.

2. Schug TT, Janesick A, Blumberg B, Heindel JJ. Endocrine disrupting chemicals and disease susceptibility. J Steroid Biochem Mol Biol. 2011;127(3-5):204-15; DOI: 10.1016/j.jsbmb.2011.08.007

3. Miller MD, Marty MA, Arcus A, Brown J, Morry D, Sandy M. Differences between children and adults: implications for risk assessment at California EPA. Int J Toxicol. 2002;21(5):403-18; DOI $10.1080 / 10915810290096630$.

4. Nagel SC, Bromfield JJ. Bisphenol a: a model endocrine disrupting chemical with a new potential mechanism of action. Endocrinology. 2013;154(6):1962-4; DOI: 10.1210/en.2013-1370.

5. Rochester JR, Bolden AL. Bisphenol S and F: A Systematic Review and Comparison of the Hormonal Activity of Bisphenol A Substitutes. Environ Health Perspect. 2015;123(7):643-50; DOI: 10.1289/ ehp.1408989.

6. Liao C, Kannan K. Concentrations and profiles of bisphenol A and other bisphenol analogues in foodstuffs from the United States and their implications for human exposure. J Agric Food Chem. 2013;61(19):4655 62; DOI: $10.1021 / \mathrm{jf} 400445 \mathrm{n}$

7. Liao C, Liu F, Guo Y, Moon H-B, Nakata H, Wu Q, Kannan K. Occurrence of Eight Bisphenol Analogues in Indoor Dust from the United States and Several Asian Countries: Implications for Human Exposure. Environmental Science \& Technology. 2012;46(16):9138-45; DOI: 10.1021/ es302004w.

8. Mendonca K, Hauser R, Calafat AM, Arbuckle TE, Duty SM. Bisphenol A concentrations in maternal breast milk and infant urine. Int Arch Occup Environ Health 2014:87(1):13-20; DOI: 10.1007/s00420-012-0834-9.

9. Crisp TM, Clegg ED, Cooper RL, Wood WP, Anderson DG, Baetcke KP, Hoffmann JL, Morrow MS, Rodier DJ, Schaeffer JE, Touart LW, Zeeman MG, Patel YM. Environmental endocrine disruption: an effects assessment and analysis. Environ Health Perspect. 1998;106 Suppl 1:11-56; DOI: 10.1289/ehp.98106s111.

10. McLachlan JA. Synergistic effect of environmental estrogens: report withdrawn. Science. 1997;277(5325):462-3.

11. J. Geyer H, Rimkus G, Scheunert I, Kaune A, Schramm K-W, Kettrup A, Zeeman M, C. G. Muir D, Hansen L, Mackay D. Bioaccumulation and Occurrence of Endocrine-Disrupting Chemicals (EDCs), Persistent Organic Pollutants (POPs), and Other Organic Compounds in Fish and Other Organisms Including Humans. 22007:1-166.

12. Street ME, Angelini S, Bernasconi S, Burgio E, Cassio A, Catellani C, Cirillo F, Deodati A, Fabbrizi E, Fanos V, Gargano G, Grossi E, Iughetti L Lazzeroni P, Mantovani A, Migliore L, Palanza P, Panzica G, Papini AM, Parmigiani S, Predieri B, Sartori C, Tridenti G, Amarri S. Current Knowledge on Endocrine Disrupting Chemicals (EDCs) from Animal Biology to Humans, from Pregnancy to Adulthood: Highlights from a Nationa Italian Meeting. Int J Mol Sci. 2018;19(6); DOI: 10.3390/ijms19061647.

13. Landrigan CP, Srivastava R, Muret-Wagstaff S, Soumerai SB, Ross-Degnan D, Graef JW, Homer CJ, Goldmann DA. Impact of a health maintenance organization hospitalist system in academic pediatrics. Pediatrics. 2002;110(4):720-8; DOI: 10.1542/peds.110.4.720.

14. LaKind JS, Amina Wilkins A, Berlin CM, Jr. Environmental chemicals in human milk: a review of levels, infant exposures and health, and guidance for future research. Toxicol Appl Pharmacol. 2004;198(2):184-208 DOI: 10.1016/j.taap.2003.08.021.

15. Breastfeeding and the use of human milk. American Academy of Pediatrics. Work Group on Breastfeeding. Pediatrics. 1997;100(6):1035-9 DOI: 10.1542 /peds.100.6.1035.
16. Dieterich CM, Felice JP, O'Sullivan E, Rasmussen KM. Breastfeeding and health outcomes for the mother-infant dyad. Pediatr Clin North Am 2013;60(1):31-48; DOI: 10.1016/j.pcl.2012.09.010.

17. Laug EP, Kunze FM, Prickett CS. Occurrence of DDT in human fat and milk. AMA Arch Ind Hyg Occup Med. 1951;3(3):245-6.

18. Landrigan PJ, Goldman LR. Children's vulnerability to toxic chemicals: a challenge and opportunity to strengthen health and environmental policy. Health Aff (Millwood). 2011;30(5):842-50; DOI: 10.1377/ hlthaff.2011.0151.

19. Massart F, Gherarducci G, Marchi B, Saggese G. Chemical Biomarkers of Human Breast Milk Pollution. Biomark Insights. 2008;3:159-69.

20. Ito S, Alcorn J. Xenobiotic transporter expression and function in the human mammary gland. Adv Drug Deliv Rev. 2003;55(5):653-65.

21. McManaman JL, Neville MC. Mammary physiology and milk secretion. Adv Drug Deliv Rev. 2003;55(5):629-41.

22. Gudi SK, K B, Kumar P. EXCRETION OF DRUGS THROUGH BREAST MILK2013. 116-24 p.

23. Tateoka Y. Bisphenol A Concentration in Breast Milk following Consumption of a Canned Coffee Drink. J Hum Lact. 2015;31(3):474-8; DOI: $10.1177 / 0890334414563732$.

24. McNamara PJ, Abbassi M. Neonatal exposure to drugs in breast milk. Pharm Res. 2004;21(4):555-66.

25. Schanker LS. Passage of drugs across body membranes. Pharmacol Rev. 1962;14:501-30.

26. Mercogliano R, Santonicola S. Investigation on bisphenol A levels in human milk and dairy supply chain: A review. Food Chem Toxicol. 2018;114:98-107; DOI: 10.1016/j.fct.2018.02.021.

27. Tsakiris IN, Goumenou M, Tzatzarakis MN, Alegakis AK, Tsitsimpikou C, Ozcagli E, Vynias D, Tsatsakis AM. Risk assessment for children exposed to DDT residues in various milk types from the Greek market. Food Chem Toxicol. 2015;75:156-65; DOI: 10.1016/j.fct.2014.11.012.

28. Tsakiris IN, Kokkinakis E, Dumanov JM, Tzatzarakis MN, Flouris AD, Vlachou M, Tsatsakis AM. Comparative evaluation of xenobiotics in human and dietary milk: persistent organic pollutants and mycotoxins. Cell Mol Biol (Noisy-le-grand). 2013;59(1):58-66.

29. Rogan WJ, Ragan NB. Evidence of effects of environmental chemicals on the endocrine system in children. Pediatrics. 2003;112(1 Pt 2):247-52.

30. Organization $\mathrm{WH}$. Joint $\mathrm{FAO} / \mathrm{WHO}$ expert meeting to review toxicological and health aspects of bisphenol A: final report, including report of stakeholder meeting on bisphenol A, 1-5 November 2010, Ottawa, Canada. 2011.

31. Volkel W, Colnot T, Csanady GA, Filser JG, Dekant W. Metabolism and kinetics of bisphenol a in humans at low doses following oral administration. Chem Res Toxicol. 2002;15(10):1281-7.

32. Domoradzki JY, Thornton CM, Pottenger LH, Hansen SC, Card TL, Mar kham DA, Dryzga MD, Shiotsuka RN, Waechter JM, Jr. Age and dose dependency of the pharmacokinetics and metabolism of bisphenol A in neonatal sprague-dawley rats following oral administration. Toxicol Sci. 2004;77(2):230-42; DOI: 10.1093/toxsci/kfh054.

33. Mielke H, Gundert-Remy U. Bisphenol A levels in blood depend on age and exposure. Toxicol Lett. 2009;190(1):32-40; DOI: 10.1016/j. toxlet.2009.06.861.

34. Fabrega F, Nadal M, Schuhmacher M, Domingo JL, Kumar V. Influence of the uncertainty in the validation of PBPK models: A case-study for PFOS and PFOA. Regul Toxicol Pharmacol. 2016;77:230-9; DOI: 10.1016/j yrtph.2016.03.009.

35. Sharma RP, Schuhmacher M, Kumar V. The development of a pregnancy PBPK Model for Bisphenol A and its evaluation with the available biomonitoring data. Sci Total Environ. 2018;624:55-68; DOI: 10.1016/j. scitotenv.2017.12.023.

36. Teeguarden JG, Waechter JM, Jr., Clewell HJ, 3rd, Covington TR, Barton HA. Evaluation of oral and intravenous route pharmacokinetics, plasma protein binding, and uterine tissue dose metrics of bisphenol A: a physiologically based pharmacokinetic approach. Toxicol Sci. 2005;85(2):823-38; DOI: 10.1093/toxsci/kfi135.

37. Edginton AN, Ritter L. Predicting plasma concentrations of bisphenol A in children younger than 2 years of age after typical feeding schedules, using a physiologically based toxicokinetic model. Environ Health Perspect. 2009;117(4):645-52; DOI: 10.1289/ehp.0800073.

38. Migeot V, Dupuis A, Cariot A, Albouy-Llaty M, Pierre F, Rabouan S. Bisphenol a and its chlorinated derivatives in human colostrum. Environ Sci Technol. 2013;47(23):13791-7; DOI: 10.1021/es403071a.

39. Cao X-L, Popovic S, Arbuckle TE, Fraser WD. Determination of free and total bisphenol A in human milk samples from Canadian women using a sensitive and selective GC-MS method. Food Additives \& Contaminants: Part A. 2015;32(1):120-5; DOI: 10.1080/19440049.2014.980855.

40. Mandrup K, Boberg J, Isling LK, Christiansen S, Hass U. Low-dose effects of bisphenol A on mammary gland development in rats. Andrology. 2016;4(4):673-83; DOI: 10.1111/andr.12193. 
41. Durando M, Kass L, Piva J, Sonnenschein C, Soto AM, Luque EH, Munoz-de-Toro M. Prenatal bisphenol A exposure induces preneoplastic lesions in the mammary gland in Wistar rats. Environ Health Perspect. 2007;115(1):80-6; DOI: 10.1289/ehp.9282.

42. Acevedo N, Davis B, Schaeberle CM, Sonnenschein C, Soto AM. Perinatally administered bisphenol a as a potential mammary gland carcinogen in rats. Environ Health Perspect. 2013;121(9):1040-6; DOI: 10.1289/ ehp.1306734.

43. Verner MA, Charbonneau M, Lopez-Carrillo L, Haddad S. Physiologically based pharmacokinetic modeling of persistent organic pollutants for lifetime exposure assessment: a new tool in breast cancer epidemiologic studies. Environ Health Perspect. 2008;116(7):886-92; DOI: 10.1289/ ehp.10917.

44. Yang M, Ryu JH, Jeon R, Kang D, Yoo KY. Effects of bisphenol A on breast cancer and its risk factors. Arch Toxicol. 2009;83(3):281-5; DOI: 10.1007/s00204-008-0364-0.

45. Kass L, Altamirano GA, Bosquiazzo VL, Luque EH, Munoz-de-Toro M. Perinatal exposure to xenoestrogens impairs mammary gland differen tiation and modifies milk composition in Wistar rats. Reprod Toxicol. 2012;33(3):390-400; DOI: 10.1016/j.reprotox.2012.02.002.

46. Paulose T, Speroni L, Sonnenschein C, Soto AM. Estrogens in the wrong place at the wrong time: Fetal BPA exposure and mammary cancer. Reprod Toxicol. 2015;54:58-65; DOI: 10.1016/j.reprotox.2014.09.012.

47. Skledar DG, Schmidt J, Fic A, Klopcic I, Trontelj J, Dolenc MS, Finel M, Masic LP. Influence of metabolism on endocrine activities of bisphenol S. Chemosphere. 2016;157:152-9; DOI: 10.1016/j.chemosphere.2016.05.027.

48. Deceuninck Y, Bichon E, Marchand P, Boquien CY, Legrand A, Boscher C, Antignac JP, Le Bizec B. Determination of bisphenol A and related substitutes/analogues in human breast milk using gas chromatography-tandem mass spectrometry. Anal Bioanal Chem. 2015;407(9):2485-97; DOI: $10.1007 / \mathrm{s} 00216-015-8469-9$.

49. Dualde P, Pardo O, S FF, Pastor A, Yusa V. Determination of four parabens and bisphenols A, F and S in human breast milk using QuEChERS and liquid chromatography coupled to mass spectrometry. J Chromatogr B Analyt Technol Biomed Life Sci. 2019;1114-1115:154-66; DOI 10.1016/j.jchromb.2019.03.004

50. Niu Y, Wang B, Zhao Y, Zhang J, Shao B. Highly Sensitive and High-Throughput Method for the Analysis of Bisphenol Analogues and Their Halogenated Derivatives in Breast Milk. J Agric Food Chem. 2017;65(48):10452-63; DOI: 10.1021/acs.jafc.7b04394.

51. Tuzimski T, Pieniazek D, Buszewicz G, Teresinski G. QuEChERS-Based Extraction Procedures for the Analysis of Bisphenols $\mathrm{S}$ and A in Breast Milk Samples by LC-QqQ-MS. J AOAC Int. 2018; DOI: 10.5740/ jaoacint.18-0297.

52. Rubin BS, Murray MK, Damassa DA, King JC, Soto AM. Perinatal exposure to low doses of bisphenol A affects body weight, patterns of estrous cyclicity, and plasma LH levels. Environ Health Perspect. 2001;109(7):675 80; DOI: 10.1289/ehp.01109675

53. Ivry Del Moral L, Le Corre L, Poirier H, Niot I, Truntzer T, Merlin JF, Rouimi P, Besnard P, Rahmani R, Chagnon MC. Obesogen effects after perinatal exposure of 4,4'-sulfonyldiphenol (Bisphenol S) in C57BL/6 mice. Toxicology. 2016;357-358:11-20; DOI: 10.1016/j.tox.2016.05.023

54. Ahmed S, Atlas E. Bisphenol S- and bisphenol A-induced adipogenesis of murine preadipocytes occurs through direct peroxisome proliferator-activated receptor gamma activation. Int J Obes (Lond) 2016;40(10):1566-73; DOI: 10.1038/ijo.2016.95.

55. Negri-Cesi P. Bisphenol A Interaction With Brain Development and Functions. Dose Response. 2015;13(2):1559325815590394; DOI: $10.1177 / 1559325815590394$

56. Palanza P, Gioiosa L, vom Saal FS, Parmigiani S. Effects of developmental exposure to bisphenol A on brain and behavior in mice. Environ Res. 2008;108(2):150-7.

57. Palanza P, Nagel SC, Parmigiani S, Vom Saal FS. Perinatal exposure to endocrine disruptors: sex, timing and behavioral endpoints. Curr Opin Behav Sci. 2016;7:69-75; DOI: 10.1016/j.cobeha.2015.11.017.

58. Palanza P, L Howdeshell K, Parmigiani S, vom Saal F. Exposure to a Low Dose of Bisphenol A during Fetal Life or in Adulthood Alters Materna Behavior in Mice. 2002:415-22.

59. Catanese MC, Vandenberg LN. Bisphenol S (BPS) Alters Maternal Behavior and Brain in Mice Exposed During Pregnancy/Lactation and Their Daughters. Endocrinology. 2017;158(3):516-30; DOI: 10.1210/ en.2016-1723.

60. Inadera H. Neurological Effects of Bisphenol A and its Analogues. Int Med Sci. 2015;12(12):926-36; DOI: 10.7150/ijms.13267.

61. Castro B, Sanchez P, Torres JM, Ortega E. Bisphenol A, bisphenol F and bisphenol S affect differently 5alpha-reductase expression and dopamine-serotonin systems in the prefrontal cortex of juvenile female rats. Environ Res. 2015;142:281-7; DOI: 10.1016/j.envres.2015.07.001.
62. Richter CA, Birnbaum LS, Farabollini F, Newbold RR, Rubin BS, Talsness CE, Vandenbergh JG, Walser-Kuntz DR, vom Saal FS. In vivo effects of bisphenol A in laboratory rodent studies. Reprod Toxicol. 2007;24(2):199224; DOI: $10.1016 /$ j.reprotox.2007.06.004

63. Christiansen S, Axelstad M, Boberg J, Vinggaard AM, Pedersen GA, Hass U. Low-dose effects of bisphenol A on early sexual development in male and female rats. Reproduction. 2014;147(4):477-87; DOI: $10.1530 /$ rep-13-0377.

64. Hass U, Christiansen S, Boberg J, Rasmussen MG, Mandrup K, Axelstad M. Low-dose effect of developmental bisphenol A exposure on sperm count and behaviour in rats. Andrology. 2016;4(4):594-607; DOI: 10.1111/andr.12176.

65. Quan C, Wang C, Duan P, Huang W, Yang K. Prenatal bisphenol a exposure leads to reproductive hazards on male offspring via the Akt/mTOR and mitochondrial apoptosis pathways: Prenatal Bisphenol a Exposure Leads to Male Reproductive Toxicity. 2016.

66. Chen Z, Zuo X, He D, Ding S, Xu F, Yang H, Jin X, Fan Y, Ying L, Tian C, Ying C. Long-term exposure to a 'safe' dose of bisphenol A reduced protein acetylation in adult rat testes. Sci Rep. 2017;7:40337; DOI: 10.1038/ srep40337.

67. Mao Z, Xia W, Chang H, Huo W, Li Y, Xu S. Paternal BPA exposure in early life alters Igf2 epigenetic status in sperm and induces pancreatic impairment in rat offspring. Toxicol Lett. 2015;238(3):30-8; DOI: 10.1016/j toxlet.2015.08.009.

68. Schonfelder G, Flick B, Mayr E, Talsness C, Paul M, Chahoud I. In utero exposure to low doses of bisphenol A lead to long-term deleterious effects in the vagina. Neoplasia. 2002;4(2):98-102; DOI: 10.1038/ sj.neo.7900212

69. Schonfelder G, Friedrich K, Paul M, Chahoud I. Developmental effects of prenatal exposure to bisphenol a on the uterus of rat offspring. Neoplasia. 2004;6(5):584-94; DOI: 10.1593/neo.04217

70. Calhoun KC, Padilla-Banks E, Jefferson WN, Liu L, Gerrish KE, Young SL, Wood CE, Hunt PA, Vandevoort CA, Williams CJ. Bisphenol A exposure alters developmental gene expression in the fetal rhesus macaque uterus. PLoS One. 2014;9(1):e85894; DOI: 10.1371/journal.pone.0085894.

71. Brehm E, Flaws JA. Transgenerational Effects of Endocrine-Disrupting Chemicals on Male and Female Reproduction. Endocrinology. 2019;160(6):1421-35; DOI: 10.1210/en.2019-00034.

72. Chen Y, Shu L, Qiu Z, Lee DY, Settle SJ, Que Hee S, Telesca D, Yang X, Allard P. Exposure to the BPA-Substitute Bisphenol S Causes Unique Alterations of Germline Function. PLoS Genet. 2016;12(7):e1006223; DOI: 10.1371/journal.pgen.1006223

73. Shi M, Sekulovski N, MacLean JA, 2nd, Hayashi K. Effects of bisphenol A analogues on reproductive functions in mice. Reprod Toxicol. 2017;73:280-91; DOI: 10.1016/j.reprotox.2017.06.134

74. Shi M, Sekulovski N, MacLean JA, 2nd, Hayashi K. Prenatal Exposure to Bisphenol A Analogues on Male Reproductive Functions in Mice. Toxicol Sci. 2018;163(2):620-31; DOI: 10.1093/toxsci/kfy061.

75. Shi M, Sekulovski N, MacLean JA, Whorton A, Hayashi K. Prenatal Exposure to Bisphenol A Analogues on Female Reproductive Functions in Mice. Toxicol Sci. 2019;168(2):561-71; DOI: 10.1093/toxsci/kfz014.

76. Shi M, Whorton AE, Sekulovski N, MacLean JA, Hayashi K. Prenatal exposure to bisphenol A, E and S induces transgenerational effects on female reproductive functions in mice. Toxicol Sci. 2019; DOI: 10.1093/toxsci/ kfz124.

77. Ahsan N, Ullah H, Ullah W, Jahan S. Comparative effects of Bisphenol S and Bisphenol A on the development of female reproductive system in rats; a neonatal exposure study. Chemosphere. 2018;197:336-43; DOI: 10.1016/j.chemosphere.2017.12.118.

78. Nevoral J, Kolinko Y, Moravec J, Zalmanova T, Hoskova K, Prokesova S, Klein P, Ghaibour K, Hosek P, Stiavnicka M, Rimnacova H, Tonar Z, Petr J, Kralickova M. Long-term exposure to very low doses of bisphenol S affects female reproduction. Reproduction. 2018;156(1):47-57; DOI 10.1530/rep-18-0092.

79. Zalmanova T, Hoskova K, Nevoral J, Adamkova K, Kott T, Sulc M, Kotikova Z, Prokesova S, Jilek F, Kralickova M, Petr J. Bisphenol S negatively af fects the meotic maturation of pig oocytes. Sci Rep. 2017;7(1):485; DOI 10.1038/s41598-017-00570-5

80. Campen KA, Lavallee M, Combelles C. The impact of bisphenol S on bovine granulosa and theca cells. Reprod Domest Anim. 2018;53(2):450-7; DOI: $10.1111 /$ rda.13130 